\title{
Schillers Wallenstein und der Adel im Königreich Böhmen
}

\author{
Von VÁClav BŮŽEK
}

Obwohl jeder historische Versuch um die Erfassung des Lebensschicksals Wallensteins in den Literatur- und Quellenverzeichnissen auf das gleichnamige Trauerspiel Friedrich Schillers verweist, schenkten die tschechischen Historiker und Historikerinnen einer kritischen Beurteilung seines historischen Inhalts keine größere Aufmerksamkeit. Sie hätten sich nicht nur mit der Beziehung des Generalissimus zum Kaiser einerseits, sondern auch mit den konfessionellen, politischen und ökonomischen Wandlungen des Adels im Königreich Böhmen während der zwanziger und dreißiger Jahre des 17. Jahrhunderts auseinandersetzen müssen ${ }^{1}$.

„Friedrich Schiller war Künstler, er war Philosoph, er war Historiker. In seinem größten Werk ist dies alles durchaus in einem“, schrieb zu Beginn der sechziger Jahre des 20. Jahrhunderts der deutsche Historiker und Publizist Golo Mann², der seine Aufmerksamkeit den historischen Kenntnissen des Autors in der dramatischen Trilogie „Wallenstein“, die in den Jahren 1796-1798 entstanden war ${ }^{3}$, widmete. Obwohl „Die Geschichte des Dreißigjährigen Krieges“ aus den Jahren 1790_ 1792 für das bedeutendste historische Werk Friedrich Schillers gehalten wird ${ }^{4}$,

${ }^{1}$ Es handelt sich um die gekürzte Fassung des wissenschaftlichen Vortrags, der am 28. Juni 2012 bei der Sitzung der Kommission für geschichtliche Landeskunde in Baden-Württemberg in Marbach am Neckar gehalten wurde.

2 Dazu Golo Mann: Schiller als Historiker. In: Jahrbuch der Deutschen Schillergesellschaft 4 (1960) S. 98-109. Hier S. 109.

${ }^{3}$ Norbert Oellers: Das Wallensteindrama und seine Stellung unter den historischen Dramen Schillers. In: Wallensteinbilder im Widerstreit. Eine historische Symbolfigur in Geschichtsschreibung und Literatur vom 17. bis zum 20. Jahrhundert (Stuttgarter Historische Forschungen 12). Hg. von Joachim Bahlcke/Christoph Kampmann. Köln/Weimar/Wien 2011. S. 95-105.- Arnd Beise: Schillers moderner Wallenstein im Spiegel der zeitgenössischen Rezeption der ersten Buchausgabe. In: Ebd. S.133-146.- Hartmut Reinhardt: Wallenstein. In: Schiller-Handbuch. Hg. von Helmut Koopmann. Stuttgart ${ }^{2} 2011$. S. 416-437.

${ }^{4}$ Theodor Schieder: Schiller als Historiker. In: Historische Zeitschrift 190 (1960) S. 3154. - Otto Dahn: Schiller, der Historiker und die Quellen. In: Schiller als Historiker. Hg. von Otto Dahn/Norbert Oellers/Ernst Osterkamp. Stuttgart/Weimar 1995. S.109-126. Milan Tordik: „Von der Parteien Gunst und Haß verwirrt schwankt sein Charakterbild in der Geschichte“. Die Gestalt Wallensteins bei Schiller und bei den tschechischen Histori- 
findet der gelehrte Leser in den Reden und Äußerungen der Hauptfiguren des Dramas „Wallenstein“ eine Reihe realer und wahrhafter historischer Ereignisse, Personen und gesellschaftlicher Zusammenhänge. Seine Handlung spielt im Westen Böhmens in Plzeň/Pilsen und Cheb/Eger während der Herbst- und Wintermonate an der Wende der Jahre 1633 und 1634, als das konfessionell und politisch gespaltene Mitteleuropa bereits sechzehn Jahre lang den Kriegsalltag erlebte ${ }^{5}$.

Schillers Wallenstein verbrachte die letzten Monate seines Lebens mit seiner Gemahlin, seiner Tochter, seinem Astrologen, den Befehlshabern der einzelnen Regimenter seiner Armee und weiterer realer wie auch fiktiver Personen, deren Lebensschicksal einstweilig der Krieg vereinte. Obwohl die wiederholten medizinischen Untersuchungen der sterblichen Überreste ergaben, dass die ungenügend behandelte Syphilis und weitere Erkrankungen Wallenstein am Lebensende große Schmerzen bereiteten, blieb Schillers Bild von diesem großen Krieger, Heerführer und Mäzen durch seine körperlichen und psychischen Leiden unverändert ${ }^{6}$. Der Autor dieses dreiteiligen Kunstwerks schilderte Wallenstein als einen unentschlossenen, unschlüssigen und dauernd zweifelnden Menschen, der mehr Vertrauen in die symbolische Sprache der Sterne als in seine Nächsten hatte ${ }^{7}$.

Der Inhalt der Dialoge in den einzelnen Akten dieses Dramas von Schiller bietet dem Leser nicht nur einen Einblick des Autors in Wallensteins Gedankenwelt, sondern gibt auch die Ansichten über sein Handeln und Benehmen wieder, die seine Familienmitglieder, Verwandten, Regimentsobersten und Soldaten zum Ausdruck brachten. Obwohl Wallenstein in allen drei Teilen des Dramas auf den ersten Blick scheinbar nur nach Wegen zu einer schnellen Beendigung des Krieges suchte, war Schiller bemüht, die Gemütsverfassung des Haupthelden zu einer künstlerischen Darstellung seiner steilen Karriere vor dem Hintergrund religiöser, politischer wie auch wirtschaftlicher Wandlungsprozesse des Adels in den böhmischen Ländern zu nutzen ${ }^{8}$. Der Autor des Dramas ließ jedoch auch die Ansichten und Haltungen

kern. In: Acta Universitatis Carolinae - Philologica 2. Germanistica Pragensia 14 (1997) S. 67-79. - Jürgen Eder: Schiller als Historiker. In: Schiller-Handbuch (wie Anm. 3) S. 695742. - Holger Mannigel: Entstehung und Wandel des Wallensteinsbilds Schillers in der „Geschichte des Dreißigjährigen Kriegs“. In: Wallensteinbilder (wie Anm. 3) S. 107-131.

${ }^{5}$ Friedrich Schiller: Wallenstein. Ein dramatisches Gedicht. Bd. I: Wallensteins Lager. Die Piccolomini. Stuttgart 2004 u. Bd. II: Wallensteins Tod. Stuttgart 2003.

${ }^{6}$ Josef Janáček: Valdštejn a jeho doba [Wallenstein und seine Zeit]. Praha 1978. S. 534535. - Josef Polišenský/Josef Kollmann: Valdštejn - ani císař, ani král [Wallenstein - weder Kaiser, noch König]. Praha 1995. S. 13.

7 Eder (wie Anm. 4) S. 695-742. - Reinhardt (wie Anm. 3) S. 416-437.

8 Josef Petráñ: Na téma mýtu Bílá hora [Zum Thema Mythos des Weißen Bergs]. In: Traditio et cultus. Miscellanea bohemica Miloslao Vlk, archiepiscopo Pragensi, ab eius collegis amicisque ad annum sexagesimum dedicata. Hg. von Zdeňka Hledíková. Praha 1993. S. 141162. - Václav Bůžek/Petr Mat’a: Wandlungen des Adels in Böhmen und Mähren im Zeitalter des Absolutismus (1620-1740). In: Der europäische Adel im Ancien Regieme. Von der Krise der ständischen Monarchien bis zur Revolution (1600-1789). Hg. von Ronald G. Asch. Köln/Weimar/Wien 2001. S.287-321. - Petr Mat'a: Landstände und Landtage in den 
der Regimentsobersten in der Armee Wallensteins, die seinen plötzlichen Sturz als Sprungbrett für ihre eigene Karriere betrachteten, nicht unbeachtet.

Friedrich Schiller stützte sich im ersten Teil seines Schauspiels auf die Reden jener Personen, die sich im Feldlager Wallensteins bei Pilsen aufhielten, um in einer künstlerischen Reduktion die Schlüsseletappen der Karriere der Hauptfigur dennoch darzustellen ${ }^{9}$. Obwohl er Wallensteins Konversion zum Katholizismus ${ }^{10}$ und

böhmischen und österreichischen Ländern (1620-1740). Von der Niedergangsgeschichte zur Interaktionsanalyse. In: Die Habsburgermonarchie 1620 bis 1740. Leistungen und Grenzen des Absolutismusparadigmas (Forschungen zur Geschichte und Kultur des östlichen Mitteleuropa 24). Hg. von Petr Mat'a /Thomas Winkelbauer. Stuttgart 2006. S. 345-400. - Václav Bǔžek: Nach dem „Weißen Berg“. Selbstreflexion und Selbststilisierung des Adels der böhmischen Länder im 17. Jahrhundert. In: Zwischen Schande und Ehre. Erinnerungsbrüche und die Kontinuität des Hauses. Legitimationsmuster und Traditionsverständnis des frühneuzeitlichen Adels in Umbruch und Krise (Veröffentlichungen des Instituts für Europäische Geschichte Mainz, Abteilung für Universalgeschichte Beiheft 73). Hg. von Martin Wrede/Horst Carl. Mainz 2007. S. 269-285. - Alessandro Catalano: Zápas o svědomí. Kardinál Arnošt Vojtěch z Harrachu (1598-1667) a protireformace v Čechách [Der Kampf um das Gewissen. Kardinal Ernst Adalbert von Harrach (1598-1667) und die Gegenreformation in Böhmen]. Praha 2008. - Václav Bůžek: Die Adelslandschaft der böhmischen Länder im 16. und 17. Jahrhundert. In: Sammeln, Lesen, Übersetzen als höfische Praxis der Frühen Neuzeit. Die böhmische Bibliothek der Fürsten Eggenberg im Kontext der Fürsten- und Fürstinnenbibliotheken der Zeit (Wolfenbütteler Forschungen 126). Hg. von Jill Bepler/Helga Meise. Wiesbaden 2010. S. 17-52.

9 Zum Leben und zur Karriere Wallensteins vgl. Hellmut Diwald: Wallenstein. München/Esslingen 1969. - Golo Mann: Wallenstein. Sein Leben erzählt von Golo Mann. Frankfurt am Main 1971. - Janáček (wie Anm. 6). - Christoph Kampmann: Reichsrebellion und kaiserliche Acht. Politische Strafjustitz im Dreißigjährigen Krieg und das Verfahren gegen Wallenstein 1634 (Schriftenreihe der Vereinigung zur Erforschung der Neueren Geschichte 21). Münster 1993.- Polišenský/Kollmann (wie Anm.6). - Diess.: Wallenstein. Feldherr des Dreißigjährigen Krieges. Köln/Weimar/Wien 1997. - Josef Kollmann: Valdštejn a evropská politika 1625-1630. Historie 1. generalátu [Wallenstein und die europäische Politik 16251630. Geschichte des 1. Generalats]. Praha 1999. - Ders.: Valdštejnův konec. Historie 2. generalátu 1631-1634 [Wallensteins Ende. Geschichte des 2. Generalats 1631-1634]. Praha 2001. - Albrecht z Valdštejna - Inter arma silent musae? [Wallenstein - Inter arma silent musae?]. Hg. von Eliška Fučíková /Ladislav Čepička. Praha 2007. - Robert Rebitsch: Wallenstein. Biografie eines Machtmenschen. Wien/Köln/Weimar 2010. - Zum historiographischen Kontext besonders Jaroslav Pánek: Proměny obrazu Albrechta z Valdštejna (Evropské téma v české perspektivě sedmi desetiletí: 1934-2007) [Die Wandlungen des Bilds Wallensteins (Das europäische Thema in der tschechischen Perspektive von sieben Jahrzehnten)]. In: Albrecht z Valdštejna (wie Anm. 9) S. 23-37. - Joachim Bablcke: Geschichtsdeutungen in nationaler Konkurrenz. Das Wallensteinbild von Josef Pekař (1870-1937) und seine Rezeption in Böhmen und der Tschechoslowakei. In: Wallensteinbilder (wie Anm.3) S. 279-313. Roland Gebrke: Nationalkonservative Historiographie im geteilten Deutschland. Das Wallensteinbild bei Hellmut Diwald. In: Ebd. S. 331-348. - Hans-Christof Kraus: Golo Manns „Wallenstein“ im Kontext seines Lebenswerkes und seiner Zeit. In: Ebd. S. 349-390.

10 Thomas Winkelbaner: Fürst und Fürstendiener. Gundaker von Liechtenstein, ein österreichischer Aristokrat des konfessionellen Zeitalters (Mitteilungen des Instituts für Österreichische Geschichtsforschung Ergänzungsband 34). Wien/München 1999. S. 98. - 
seine vorteilhafte eheliche Verbindung mit der reichen Witwe Lukretia Neksch von Landek ${ }^{11}$, durch die er ausgedehnte Herrschaften in Nordmähren erworben hatte, unbeachtet ließ, machte er auf sein Studium in Altdorf und sein lebenslanges Vertrauen auf die Sprache der Horoskope aufmerksam. Friedrich Schiller bemerkte ganz richtig, dass der ursprünglich nicht wohlhabende böhmische Adlige seinen außergewöhnlichen gesellschaftlichen Aufstieg den Habsburgern und dem Kriegsunternehmen zu verdanken hatte. Obwohl er am böhmischen Ständeaufstand nicht teilgenommen hatte, erwarb er nach 1620 für seine treuen Dienste am Hause Habsburg ausgedehnten Grundbesitz in Nordostböhmen, der von den evangelischen Opponenten der herrschenden Dynastie konfisziert worden war, besonders hierbei die Herrschaften Frýdlant/Friedland und Liberec/Reichenberg ${ }^{12}$. Wallenstein wurde plötzlich nicht nur zum reichsten Adligen im Königreich Böhmen, sondern im Jahre 1623 mit der Würde des Herzogs von Friedland sogar in den Reichsfürstenstand erhoben. Die künstlerische Verknappung erlaubte Schiller jedoch nicht, die politische Bedeutung der zweiten Ehe Wallensteins mit Isabella Katharina von Harrach, die ihm vorübergehend die Wege in das kaum durchschaubare Milieu des Kaiserhofes in Wien ebnete, ausreichend zu würdigen ${ }^{13}$.

Trotz der früheren Erfahrungen auf dem Schlachtfeld berief Kaiser Ferdinand II. Wallenstein erst im Jahre 1625 in seine militärischen Dienste. Der Autor des Dramas hielt die Ernennung Wallensteins zum General und Obersten Feldhauptmann und zum General des Ozeanischen und Baltischen Meeres im Frühling 1628, die nicht nur mit dem Erwerb des Herzogtums Mecklenburg im Norden des Römisch-Deutschen Reiches, sondern auch mit dem Erwerb der Fürstentümer Zagań/Sagan und später Głogów/Glogau in Schlesien verbunden war, für den Höhepunkt seiner militärischen Karriere in den kaiserlichen Diensten. Friedrich Schiller unterließ es jedoch, eine ausführliche Erörterung jener Umstände zu geben, die am

Ders.: Karrieristen oder fromme Männer? Adelige Konvertiten in den böhmischen und österreichischen Ländern um 1600. In: Frühneuzeit-Info 10 (1999) S. 9-20.

11 Vlasta Fialová: Lukrecie Nekšovna z Landeku, první manželka Albrechta z Valdštejna [Lukretia Neksch von Landek, die erste Ehefrau Wallensteins]. In: Český časopis historický 40 (1934) S. 125-136.

12 Tomáš V. Bílek: Dějiny konfiskací v Čechách po roce 1618 [Geschichte der Konfiskationen in Böhmen nach dem Jahre 1618]. Band I/II. Praha 1882-1883. Hier Bd. II S. 732-832. - Petr Čornej: Vliv pobělohorských konfiskací na skladbu feudální tř́ídy [Strukturänderungen der Feudalklasse als Folgen der Konfiskationen im Zeitalter nach der Schlacht am Weißen Berge]. In: Acta Universitatis Carolinae - Philosophica et historica 1. Studia historica 14 (1976) S. 165-194. Hier S. 180 f.

${ }_{13}$ Mark Hengerer: Kaiserhof und Adel in der Mitte des 17. Jahrhunderts. Eine Kommunikationsgeschichte der Macht in der Vormoderne (Historische Kulturwissenschaft 3). Konstanz 2004. - Christoph Kampmann: Zweiter Mann im Staat oder Staat im Staat? Zur Stellung Wallensteins in der Administration Kaiser Ferdinands II. In: Der zweite Mann im Staat. Oberste Amtsträger und Favoriten im Umkreis der Reichsfürsten in der Frühen Neuzeit (Zeitschrift für historische Forschung Beiheft 32). Hg. von Michael Kaiser/Andreas Pečar. Berlin 2003. S. 295-315. 
Ende des Sommers 1630 zur Abberufung Wallensteins als Oberbefehlshaber der kaiserlichen Armee und zu seiner neuen Ernennung an ihre Spitze mit dem Rang eines Generalissimus im Jahre 1632 beitrugen. Letztere stand im Zusammenhang mit dem Einfall des Königs von Schweden, Gustav II. Adolf, ins Römisch-Deutsche Reich ${ }^{14}$.

Dagegen beschrieb Friedrich Schiller im ersten Teil seines Dramas sehr zutreffend Wallensteins Grundsätze, die er bei der Aufstellung seiner Armee zur Geltung brachte. Der Herzog von Friedland verstand das moderne Kriegswesen nicht als bloße Kriegsführung, sondern er achtete auf die Werbung von Soldaten und Befehlshabern, auf ihre Ausrüstung, Bewaffnung und Ausbildung wie auch auf die regelmäßige Verpflegung, Versorgung und Auszahlung der Besoldung ${ }^{15}$. Die Ansprüche an den ökonomischen Unterhalt eines vielköpfigen Heeres beeinflussten die Struktur einzelner Zweige der landwirtschaftlichen und handwerklichen Produktion auf den Herrschaften des Herzogtums Friedland ${ }^{16}$. Obwohl Schiller in den Reden der Soldaten erwähnte, dass der Herzog zu Friedland neue finanzielle Mittel für den Unterhalt der Armee und die Kriegsführung verlangte, hatte er jedoch keinerlei Ahnung von seinen Krediten und anderen finanziellen Operationen, die gemeinen Soldaten verborgen blieben ${ }^{17}$.

Wenn man im Feldlager Wallensteins bei Pilsen über strenge Disziplin und Ordnung sprach, suchte der Autor nach sittlichen und moralischen Vorbildern, die die Soldaten und ihre Befehlshaber aus verschiedenen europäischen Ländern auf dem Schlachtfeld hätten verbinden können. Über die fehlende geistige Botschaft des Krieges sprach jedoch ein Kapuzinermönch mit Vorwurf in seiner Stimme, der nicht nur die Beutezüge der Wallensteinischen Soldaten verurteilte, sondern auf die Ideen des christlichen Rittertums verwies ${ }^{18}$. Durch seine Worte über den Verfall

${ }^{14}$ Kollmann, Valdštejn (wie Anm. 9).- Ders.: Valdštejnův konec (wie Anm. 9).

${ }^{15}$ Ladislav Čepička: Valdštejnova ARMADA. Pokus o rekonstrukci [Die Armee Wallensteins. Ein Versuch um die Rekonstruktion]. In: Albrecht z Valdštejna (wie Anm. 9) S. 271281.

16 Anton Ernstberger: Wallenstein als Volkswirt im Herzogtum Friedland (Prager Studien aus dem Gebiet der Geschichtswissenschaft 19). Reichenberg 1929. - Josef Janáček: Jičín als Hauptstadt des Herzogtums Friedland. Zur Frage des Aufschwungs der Stadt im Rahmen der grundherrschaftlichen Domäne im 17. Jahrhundert. In: Die Städte Mitteleuropas im 17. und 18. Jahrhundert. Hg. von Wilhelm Rausch. Linz 1981. S. 107-118. - Dana Štefanová: Erbschaftspraxis, Besitztransfer und Handlungsspielräume von Untertanen in der Gutsherrschaft. Die Herrschaft Frýdlant in Nordböhmen 1558-1750 (Sozial- und wirtschaftshistorische Studien 34). Wien 2009. - Antonín Kostlán: Albrecht z Valdštejna jako investor do svého vlastního osudu. Ekonomické aspekty jedné raně novověké kariéry [Wallenstein als Investor in sein eigenes Schicksal. Ökonomische Aspekte einer frühneuzeitlichen Karriere]. In: Albrecht z Valdštejna (wie Anm. 9) S. 38-61.

17 Mit der Zusammenfassung älterer Literatur Steffen Leins: Das Prager Münzkonsortium 1622/23. Ein Kapitalgeschäft im Dreißigjährigen Krieg am Rand der Katastrophe. Münster 2012.

18 Andreas Wang: Der Miles Christianus im 16. und 17. Jahrhundert und seine mittelalter- 
christlicher Werte, Die Christenheit tranert in Sack und Asche, der Soldat füllt sich nur die Tasche ${ }^{19}$, erhob Schiller eine moralische Anklage des Krieges, der einerseits nur Leiden mit sich brachte, andererseits jedoch einen fruchtbaren Boden für einen schnellen gesellschaftlichen Aufstieg darstellte ${ }^{20}$. Wenn die Soldaten und Offiziere nicht mehr die Werte christlicher Ritter miteinander verbanden, interessierte sich der Autor dafür, wem sie eigentlich vertrauten. In ihren Augen ersetzte Wallenstein die Tugenden christlicher Ritter, denn er ermöglichte vielen Männern verschiedener gesellschaftlicher und nationaler Herkunft, an einem langwierigen Kriegskonflikt teilnehmen zu dürfen ${ }^{21}$. Obwohl die gemeinen Soldaten im Feldlager bei Pilsen erklärten, sie hätten ihr Leben dem Dienst an Wallenstein geweiht, sehnten sich ihre Befehlshaber nach Unabhängigkeit und nach dem Erwerb von Grundbesitz. Vielleicht wollte Schiller schon im ersten Teil seines Dramas andeuten, dass den immer näher rückenden Sturz Wallensteins eine Verschwörung seiner engsten Obersten und Generäle adliger wie auch nichtadliger Herkunft begleiten sollte, zu denen dieser bis zur letzten Stunde seines Lebens grenzenloses Vertrauen hatte ${ }^{22}$. Einblick in die Gedankenwelt Wallensteins vermittelten im Feldlager bei Pilsen die Stimmen von Soldaten, die seine eigenen Gefühle zum Ausdruck brachten. In ihnen vereinten sich Ehrgeiz, Unentschlossenheit und Unsicherheit. Durch ihre Worte präsentierte Friedrich Schiller Wallenstein als eine außergewöhnlich reiche, mächtige und unabhängige Persönlichkeit, die über ein ausgedehntes Gebiet herrschte, eigene Münzen prägte und das Oberkommando über eine riesige Armee inne hatte. Wallenstein, der mit dem Titel eines Reichsfürsten prahlen konnte, fiel im Hinblick auf seine außerordentliche Macht tatsächlich die souveräne Stellung eines Königs zu, er blieb aber trotzdem immer noch des Kaisers Knecht ${ }^{23}$.

Obwohl der steile Aufstieg des Herzogs von Friedland allgemein Unmut und Hass hervorrief, widmete Friedrich Schiller im zweiten Teil seines Schauspiels mit dem Titel „Die Piccolomini“ dem engsten wie auch breiteren sozialen Umfeld Wallensteins seine Aufmerksamkeit, um mit künstlerischen Mitteln weitere Stufen seiner Karriere schildern zu können ${ }^{24}$. Nach der Schlacht bei Steinau im Herbst 1633 war in Wien klar, dass der Unterhalt der Armee Wallensteins, die der Meinung Ferdinands II. nach in erster Linie Maximilian von Bayern in seinen militärischen

liche Tradition. Ein Beitrag zum Verhältnis von sprachlicher und graphischer Bildlichkeit. Bern 1975.

19 Schiller (wie Anm. 5) Bd. 1. S. 26. - Schieder (wie Anm.4). - Ernst Schulin: Schillers Interesse an Aufstandsgeschichte. In: Schiller als Historiker (wie Anm. 4) S. 137-148.

20 Petr Mat'a: Svět ćeské aristokracie (1500-1700) [Die Welt der böhmischen Aristokratie (1500-1700)]. Praha 2004. S. 458-464.

${ }^{21}$ Rebitsch (wie Anm. 9) S. 158-176.

22 Reinhardt (wie Anm. 3) S. 416-437.

${ }^{23}$ Der Herzog ist gewaltig und hochverständig, aber er bleibt doch, schlecht und recht, wie wir alle, des Kaisers Knecht. Dazu Schiller (wie Anm. 5) Bd. 1. S. 37.

${ }^{24}$ Polišenský/Kollmann (wie Anm.6) S.185-210. - Kollmann, Valdštejnův konec (wie Anm. 9) S. 75-142. 
Auseinandersetzungen mit den Schweden in der Umgebung von Regensburg unterstützen sollte, großen finanziellen Aufwand erforderte. Die Stellungnahme des Kaisers überbrachten der Geheimrat Maximilian von Trauttmansdorf und der Hofkriegsrat Gerhard von Questenberg nach Pilsen. Beide Anhänger Ferdinands II. besaßen kleinere Herrschaften in Westböhmen, die sie während der ersten Konfiskationen des Vermögens böhmischer evangelischer Adliger nach 1620 erwarben $^{25}$. In Schillers Drama sprach nur Gerhard von Questenberg mit einigen Obersten des Wallensteinischen Heeres. Aus dem Inhalt ihrer Gespräche ging hervor, dass Wallenstein die Aufrechterhaltung der regelmäßigen Kommunikation mit einflussreichen Würdenträgern am Kaiserhof unterschätzte.

In Wien bildete sich inzwischen eine starke Opposition gegen ihn heraus, an deren Spitze Wilhelm Slawata von Chlum und Koschumberg und Jaroslav Borzita von Martinitz standen ${ }^{26}$. Beide einflussreichen böhmischen Adligen katholischen Bekenntnisses konnten Wallenstein nicht vergessen, dass er nach der Niederlage des böhmischen Ständeaufstands den größten Teil an den Konfiskationen der Güter des evangelischen Adels in Böhmen erworben hatte und gleichzeitig in den Reichsfürstenstand erhoben worden war ${ }^{27}$. Schillers Wallenstein hielt beide Adlige für Schützlinge des Kaisers, mit dessen Hilfe sie in hohe Landes- und Hofämter gelangt waren ${ }^{28}$. Noch empörter war Gerhard von Questenberg, nachdem er festgestellt hatte, dass sich Wallenstein nicht nach den Beschlüssen der Vereinbarung von Göllersdorf vom April 1632 richtete. Denn dieser wollte die Armee nicht den politischen Interessen des Kaisers entsprechend zur Verfügung stellen.

Weitere Gegner Wallensteins im Umfeld Ferdinands II. stellte Friedrich Schiller in einem Gespräch mit seiner Gemahlin vor, die gemeinsam mit ihrer Tochter aus Kärnten nach Pilsen reiste, mit einer Unterbrechung am Kaiserhof in Wien. Auch wenn Wallenstein der Vater von Maria Elisabeth war, handelt es sich in Schillers Darstellung bei ihr um eine fiktive Person. Die historische Forschung bestätigte die Behauptungen beider Frauen über die angespannten Beziehungen Wallensteins

25 Bílek (wie Anm.12) I. Bd. S. 98, 203, 329-331, 447-448, 633. II. Bd. S. 1207-1208. Winkelbauer, Fürst (wie Anm.10) S.180-189. - Marie Mirková: Řád zlatého rouna a rodová prestiž v představách Adama Matyáše z Trauttmansdorffu [Orden vom Goldenen Vlies und das Prestige des Hauses in der Vorstellung von Adam Matthias von Trauttmansdorff]. In: Utváření identity ve vrstvách paměti [Die Herausbildung der Identität in den Gedächtnisschichten] (Opera historica 15). Hg. von Václav Bůžek/Jaroslav Dibelka. České Budějovice 2011. S. 249-282. - Hengerer (wie Anm. 13) S.163ff.

${ }^{26}$ Rebitsch (wie Anm. 9) S. 201-210. - Miloslav Volf: Jaroslav Bořita z Martinic po defenestraci [Jaroslav Borzita von Martinitz nach dem Fenstersturz]. In: Středočeský sborník historický 7 (1972) S. 76-90. - Winkelbaner, Fürst (wie Anm. 10) S. 107-119. - Bůžek: Nach dem „Weißen Berg“ (wie Anm. 8) S. 273-276.

27 Bílek (wie Anm. 12) II. Bd. S. 732-832.

${ }_{28} \mathrm{Da}$, der Slawata und derMartinitz, auf die der Kaiser, allen guten Böhmen zum Ärgernisse, Gnadengaben häuft - die sich vom Raube der vertriebnen Bürger mästen, die von der allgemeinen Fäulnis wachsen, allein im öffentlichen Unglück ernten [...]. Dazu Schiller (wie Anm.5) Bd.1. S. 54. 
zu Peter Wilhelm Lamormain und Maximilian von Bayern ${ }^{29}$. Während der einflussreiche kaiserliche Beichtvater Wallenstein starke konfessionelle Toleranz vorwarf, war dem Kurfürsten von Bayern sein plötzlicher gesellschaftlicher Aufstieg ein Dorn im Auge. Dagegen bezweifelte die Geschichtsschreibung Schillers entstellte Vorstellung über die zugespitzten Beziehungen des Herzogs von Friedland zu den Repräsentanten spanischer Interessen am Wiener Hof, zu denen an erster Stelle der zukünftige Kaiser Ferdinand III. gehörte. Für den König von Spanien, Philipp IV., verkörperte Wallenstein die militärischen Erfolge der Habsburger. Dies war auch der Grund, warum er ihm im Jahre 1628 den Orden vom Goldenen Vlies verlieh.

In den folgenden Auftritten schildert Schiller die Handlungen aller bedeutenden Regimentsobristen der Armee Wallensteins, die zu den geplanten Schritten ihres Generalissimus eine entgegengesetzte Stellung einnahmen. Große Aufmerksamkeit schenkte er den unterschiedlichen Ansichten Ottavio Piccolominis und Adam Erdmann Trčkas von Lípa. Der italienische Feldherr mit dem Rang eines Feldmarschalls verharrte während des Treffens in Pilsen bei der Vorstellung, Wallenstein werde die kaiserliche Armee gegen die Habsburger wenden, um den böhmischen Thron an sich zu reißen. Obwohl der in Pisa Gebürtige dem Generalissimus seine Treue beteuerte, schickte er durch Maximilian von Trauttmansdorf und Gerhard von Questenberg Informationen aus seiner Umgebung nach Wien ${ }^{30}$.

Während Schiller Ottavio Piccolomini als verräterischen Intriganten darstellt, der nach Macht und Vermögen trachtete, ließ er Adam Erdmann Trčka von Lípa in einem viel günstigeren Licht erscheinen. Der Autor des Dramas hielt es für kein Geheimnis, dass Wallenstein und Trčka den alten böhmischen Adelsgeschlechtern entstammten. Beide adlige Kriegsmänner verbanden nicht nur verwandtschaftliche Bande einer Schwägerschaft, sondern auch ihre Konversion zum katholischen Glauben, zu der sich Adam Erdmann gemeinsam mit seinem Vater Johann Rudolf Trčka von Lípa nach der Schlacht am Weißen Berg entschlossen hatte. Seine Mutter Maria Magdalena von Trčka, geborene von Lobkowicz, erhielt von Ferdinand II. eine Sondergenehmigung, gemäß der sie das Königreich Böhmen nicht verlassen musste, obwohl sie auf ihren evangelischen Glauben nicht verzichtete. Die Erteilung dieser besonderen Begünstigung beeinflusste sie durch eine Kreditgewährung an den Kaiser. Als Ersatz für das nicht abbezahlte Darlehen erhielt sie vom Herrscher zu Beginn der zwanziger Jahre des 17. Jahrhunderts konfiszierte Güter, die sie dem Grundbesitz der Familie Trčka von Lípa in Ostböhmen anschloss. Die moderne historische Forschung bestätigt, dass die Mutter Adam Erdmann Trčkas beim Ankauf konfiszierter Güter im Königreich Böhmen damals nur von Wallenstein überholte wurde. Obwohl Maria Magdalena Trčka zu Beginn des Jahres 1633

${ }_{29}$ Rebitsch (wie Anm. 9) S. 207-208.

30 Rebitsch (wie Anm. 9) S. 171-176. - Thomas M. Barker: Generalleutnant Ottavio Fürst Piccolomini. Zur Korrektur eines ungerechten historischen Urteils. In: Österreichische Osthefte 22 (1980) S. 322-369. 
gestorben war, gliederte Friedrich Schiller wahrscheinlich irrtümlich ihre Figur in sein Drama ein, wo sie die Rolle einer Lebensstütze ihres Sohnes einnahm ${ }^{31}$.

Als Wallenstein im Dezember 1633 die Wiener Hofburg darüber benachrichtigte, dass sein Heer das Winterquartier in der Umgebung von Pilsen nicht verlassen und am Feldzug gegen die schwedischen Truppen in der Umgebung von Regensburg nicht teilnehmen werde, hielt der Kaiser diese Entscheidung des Generalissimus für Ungehorsam. Den darauf folgenden Unterredungen Ferdinands II. mit seinem Geheimrat Gundakar von Liechtenstein bezüglich einer eventuellen Beschuldigung Wallensteins wurde in Schillers Drama kaum Aufmerksamkeit geschenkt ${ }^{32}$. Das Ergebnis der Ermittlung Liechtensteins war ein schriftliches Gutachten vom 11. Januar 1634, womit er Wallenstein nicht nur des Ungehorsams, sondern vor allem der Untergrabung der Autorität des Kaisers als Oberbefehlshaber der kaiserlichen Armee beschuldigte. Es war besonders Adam Erdmann Trčka, der in Schillers Darlegung gemeinsam mit dem brandenburgischen Offizier Christian Freiherr von Ilow den zögernden Wallenstein zu einer entscheidenden Tat bewog. Der Generalissimus wandte für einen kurzen Augenblick seine Aufmerksamkeit von der Sprache der Sterne ab und verordnete den Obristen seiner Regimenter, ihm zu huldigen und den Treueeid schriftlich zu bestätigen.

Das beabsichtigte Verhalten Wallensteins veranlasste Schiller zu einer merkwürdigen Betrachtung über die altehrwürdigen Werte ständischer und religiöser Freiheiten im Königreich Böhmen ${ }^{33}$. In den Reden der Heerführer und ihrer Bediensteten an der Gastmahltafel war zu hören, dass durch den Fenstersturz der königlichen Statthalter Wilhelm Slawata von Chlum und Koschumberg, Jaroslav Borzita von Martinitz und des Kanzleisekretärs Philipp Fabricius aus den Fenstern der böhmischen Hofkanzlei auf der Prager Burg am 23. Mai 1618 der langwierige Krieg ausgelöst wurde ${ }^{34}$. Dieser habe viele Einwohner des Königreichs Böhmen um ihre menschliche Würde gebracht, da sie das Recht auf die freie Glaubenswahl verloren

31 Deník rudolfinského dvořana. Adam mladší z Valdštejna 1602-1633 [Das Tagebuch eines Rudolfinischen Hofmannes. Adam der Jüngere von Waldstein 1602-1633]. Hg. von Marie Koldinská/Petr Mat’a. Praha 1997. S. 327, 376-377, 380. - Bílek (wie Anm. 12) II. Bd. S. 684-714. - Čornej (wie Anm. 12) S.178-181.

32 Winkelbaner, Fürst (wie Anm. 10) S. 223-226.

33 Zdeněk Vybiral: Politická komunikace aristokratické společnosti českých zemí na počátku novověku [Die politische Kommunikation der aristokratischen Gesellschaft der böhmischen Länder zu Beginn der Neuzeit] (Monographia historica 6). České Budějovice 2005. S. 39-119. - Václav Bỉžek/Zdeněk Vybiral: Freiheit in Böhmen und Mähren zwischen Hussitismus und Dreißigjährigem Krieg. In: Kollektive Freiheitsvorstellungen im Frühneuzeitlichen Europa (1400-1850). Hg. von Georg Schmidt/Martin van Gelderen/ Christopher Snigula. Frankfurt am Main u. a. 2006. S. 239-250.

${ }^{34}$ Josef Polišenský: Der Krieg und die Gesellschaft in Europa 1618-1648 (Documenta Bohemica Bellum Tricennale illustrantia I). Praha 1971. - Petráñ (wie Anm. 8) S. 141-162. Olivier Chaline: La bataille de la Montagne Blanche (8 novembre 1620). Un mystique chez les guerriers. Paris 1999. 
und viele von ihnen sogar aus der Heimat ins Exil verbannt wurden ${ }^{35}$. Schiller war sich wohl bewusst, dass der hussitische Kelch, für den Jan Žižka und seine Gotteskämpfer in den zwanziger Jahres des 15. Jahrhunderts in vielen Schlachten ihr Leben eingesetzt hatten ${ }^{36}$, ein Symbol des freien Glaubens war. Deswegen legte er besonderen Nachdruck auf den Majestätsbrief Rudolfs II. aus dem Jahre 1609, der im Königreich Böhmen das Recht auf die Glaubensfreiheit ungeachtet der sozialen Zugehörigkeit des Gläubigen bestätigte ${ }^{37}$. Als einige Obersten und ihre Bediensteten in Schillers Drama ganz offen darauf aufmerksam machten, dass alle hussitischen Kämpfer dem Vorbild Jan Žižkas, Prokop Holýs und anderer kühner Hauptmänner gefolgt waren, deutete der Autor mit Verweis auf die Landestradition $a^{38}$, dass die Obersten der Regimenter Wallensteins an der Seite ihres Generalissimus bleiben sollten. Damit wurden - im übertragenen Sinne - jedoch die Ideen christlicher Ritter des späten Mittelalters durch die erwartete Treue dem Kaiser gegenüber ersetzt.

Obwohl Schiller die Verneuerte Landesordnung aus dem Jahre 1627 nicht erwähnte, bereitete es ihm keine Schwierigkeiten, in einer künstlerischen Verkürzung ihre rechtlichen Folgen für das Königreich Böhmen zu erfassen ${ }^{39}$. Zu ihnen

35 Bůžek/Mat’a (wie Anm. 8) S. 292-297. - Bůžek, Nach dem „Weißen Berg“ (wie Anm. 8) S. 270-271.

${ }^{36}$ František Šmahel: Die Hussitische Revolution (Monumenta Germaniae Historica Schriften 43). Bd. I-III. Hannover 2002. S. 1007-1496. - Ders.: Husitské Čechy. Struktury, procesy, ideje [Das hussitische Böhmen. Strukturen, Prozesse, Ideen]. Praha 2001. S. 429494. - Winfried Eberhard: Entstehungsbedingungen für öffentliche Toleranz am Beispiel des Kuttenberger Religionsfriedens von 1485. In: Communio Viatorum - A Theological Quarterly 29 (1986) S. 129-154.

37 Jiří Just: 9. 7. 1609. Rudolfův majestát. Světla a stíny náboženské svobody [9. 7. 1609. Der Majestätsbrief Rudolfs II. Licht und Schatten der Religionsfreiheit]. Praha 2009. S. 53 80. - Ein Bruderzwist im Hause Habsburg (1608-1611) (Opera Historica 14. Editio Universitatis Bohemiae Meridionalis). Hg. von Václav Bůžek. České Budějovice 2010. - Jaroslav Pánek: Majestát z roku 1609 jako téma novodobé české historiografie [Der Majestätsbrief aus dem Jahre 1609 als ein Thema der neuzeitlichen tschechischen Geschichtsschreibung]. In: Český časopis historický 108 (2010) S. 220-243.

38 Jaroslav Pánek: Husitství jako politický argument v předbělohorské době [Das Hussitentum als ein politisches Argument in der Zeit vor der Schlacht am Weißen Berg]. In: Zrození mýtu. Dva životy husitské epochy [Die Entstehung eines Mythos. Zwei Leben der hussitischen Epoche]. Hg. von Robert Novotný/Petr Šámal u.a. Praha/Litomyšl 2011. S. 309-319.

39 Obnovené právo a zř́izení zemské dědičného království Českého [Die Verneuerte Recht- und Landesordnung des erblichen Königreichs Böhmen]. Hg. von Hermenegild Jireček. Praha 1888. - Hans-Wolfgang Berghausen: Die „Verneuerte Landesordnung“ in Böhmen 1627: ein Grunddokument des habsburgischen Absolutismus. In: Historische Zeitschrift 272 (2001) S. 327-351. - Jaroslav Pánek: Od české konfederace k Obnovenému zř́izení zemskému (Kontinuita a diskontinuita v proměnách českého státu a jeho ústavního zř́zení na pomezí stavovství a absolutismu) [Von der böhmischen Konföderation zur Verneuerten Landesordnung (Kontinuität und Diskontinuität in Wandlungen des böhmischen Staates und seiner Verfassung an der Scheide zwischen dem Ständewesen und Absolutismus)]. In: 
gehörten vor allem die Erblichkeit der böhmischen Krone für die Habsburger und die Verkündung des katholischen Glaubens als einzige zugelassene Konfession. In den angedeuteten Zusammenhängen des Dramas stellt sich die Frage, ob Schiller auch die Möglichkeit in Erwägung zog, dass Wallenstein - mit Hinblick auf seine böhmische adlige Abstammung - tatsächlich seine Armee gegen den Kaiser aus dem Hause Habsburg hätte wenden können, die Hauptstadt des Königreichs Böhmen erobert und den böhmischen Thron bestiegen hätte, um somit zur Wiederherstellung der ständischen und religiösen Freiheit seinen Beitrag zu leisten. Obwohl die tschechische Geschichtsschreibung nicht ganz ausschloss, dass der Generalissimus noch zu Beginn des Jahres 1634 auf eine schnelle Beendigung des Krieges und auf den Einsatz seiner Armee zur Verteidigung der böhmischen Länder vor den eventuellen Angriffen sächsischer und schwedischer Truppen bedacht gewesen sein könnte, lehnte sie sein Interesse an der Eroberung der Prager Burg eindeutig ab. Einerseits hing Wallenstein durch seine Interessen viel zu tief im Römisch-Deutschen Reich verhaftet, andererseits war es trotz seiner konfessionellen Toleranz kaum vorstellbar, dass er sich für die Glaubensfreiheit gemäß des Majestätsbriefes Rudolfs II., der für ungültig erklärt wurde, eingesetzt hätte ${ }^{40}$.

Sobald man in Wien erfuhr, dass sich im ersten Pilsner Revers vom 12. Januar 1634 die untergeordneten Obersten und Generäle der Regimenter Wallensteins verpflichteten, das Treuegelöbnis nur ihrem Generalissimus entgegenzubringen, ohne den Kaiser als Oberhaupt seiner eigenen Armee zu erwähnen, gelangte man zur Überzeugung, dass die beabsichtigten Schritte des Herzogs von Friedland für Ferdinand II. eine ernsthafte Bedrohung darstellten. Obwohl Ottavio Piccolomini dem Herzog von Friedland das Treuegelöbnis unterzeichnete, gehörte er zusammen mit Johann von Aldringen, Rudolf von Colloredo-Waldsee, Matthias Gallas und Balthasar Marradas zu seinen Erzfeinden. Die machtpolitische Bedeutung ihrer konspirativen Treffen auf dem südböhmischen Schloss Hluboká/Frauenberg und im schlesischen Glogau ließ Schiller in seinem Drama unbeachtet ${ }^{41}$.

Das Misstrauen auf der Wiener Hofburg intensivierte eine schriftliche Anzeige Ottavio Piccolominis, der Wallenstein und seinen Vertrauten Wilhelm Wchynski von Wchynitz einer Verschwörung gegen den Kaiser beschuldigte. Als Johann Ulrich von Eggenberg, Maximilian von Trauttmansdorf, Anton von Wolfradt und weitere enge Verbündete des Herrschers den Inhalt des Schreibens in Wien untersucht hatten, empfahlen sie Ferdinand II., er solle Wallenstein von der Stelle des Oberbefehlshabers der kaiserlichen Armee unverzüglich absetzen, da sein Han-

Vývoj české ústavnosti v letech 1618-1918 [Die Entwicklung der böhmischen Verfassungsform in den Jahren 1618-1918]. Hg. von Karel Malý/Ladislav Soukup. Praha 2006. S. 13-29.

40 Josef Pekař: Valdštejn 1630-1634. Dějiny Valdštejnského spiknutí [Wallenstein 16301634. Geschichte der Wallensteinischen Verschwörung]. Band I/II. Praha 1934. S. 208. - Janáček (wie Anm.6) S.418-423.- Kollmann: Valdštejnův konec (wie Anm. 9) S. 224-227. Kostlán (wie Anm. 16) S.60-61.

${ }^{41}$ Polišenský/Kollmann (wie Anm.6) S. 203-205. 
deln im Widerspruch zu den Interessen des Hauses Habsburg stünde. Sobald der Kaiser Wallenstein - nach einem lange verheimlichten Beschluss - am 24. Januar 1634 für abgesetzt erklärt hatte, war es nur eine Frage der Zeit, wann der Herzog von Friedland als notorischer Reichsrebell im Rahmen der Reichsacht zum Verlust der Ehre, des Besitzes und des Lebens verurteilt werden würde ${ }^{42}$. Gleichzeitig begnadigte der Herrscher außer Adam Erdmann Trčka von Lípa, Wilhelm Wchynski von Wchynitz und Christian Freiherr von Ilow alle anderen Truppenführer, die im ersten Pilsner Revers Wallenstein die Treue geschworen hatten. Die Bestallung als Oberbefehlshaber der kaiserlichen Armee erhielt Matthias Gallas. Der in Trento/ Trient Gebürtige war neben dem vorzeitig gestorbenen dänischen General Heinrich Graf von Holk lange Zeit einer der wichtigsten Offiziere in der Armee Wallensteins, dem er seine schnelle militärische Karriere und seinen gesellschaftlichen Aufstieg zu verdanken hatte ${ }^{43}$.

Im dritten Teil seines Schauspiels unter dem Titel „Wallensteins Tod“ bringt Friedrich Schiller eine Reihe emotionell zugespitzter Auftritte meisterhaft hervor. Durch sie wollte er die Charaktere seiner Hauptfiguren eingehender vorstellen. Um die Gedankenwelt Wallensteins verstehen zu können, musste er die Handlungen und das Verhalten nicht nur des verräterischen Ottavio Piccolomini, sondern auch anderer untergeordneter Truppenführer - Johann Ludwig von Isolani, Walter Buttler oder Adam Erdmann Trčka von Lípa - kennenlernen, die zum engen Umkreis des Herzogs von Friedland gehörten ${ }^{44}$. Schillers Wallenstein wollte lange nicht glauben, dass ihn die Mehrheit seiner Truppenführer, die auf Drängen Ottavio Piccolominis dem Kaiser gegenüber das Treuegelöbnis ablegten, verlassen hatte. Für ihre Loyalität erwarteten sie doch die Verleihung der Grafenwürde und den Erwerb von Grundbesitz ${ }^{45}$.

Obwohl sich nur fünf Regimenter unter dem Kommando Adam Erdmann Trčkas von Lípa an die Seite des abgesetzten Generalissimus stellten, spielte Schillers Wallenstein mit dem Gedanken, ein Bündnis mit Schweden und Sachsen zu schließen, das wahrscheinlich zur Beendigung des Krieges hätte führen können, wobei es sich freilich um Hochverrat gehandelt hätte. Der Autor des Dramas verurteilt das verschwörerische Verhalten Wallensteins in der unglaubwürdigen Geschichte über die Beschlagnahmung jener Dokumente, die den Oberbefehlshaber des kai-

${ }^{42}$ Kampmann (wie Anm. 9). - Ders.: Vídeňský dvůr a Valdštejnův pád. Říšské právo a politická trestní justice v 17. století [Der Wiener Hof und der Fall Wallensteins. Reichsrecht und politische Strafjustitz im 17. Jahrhundert]. In: Folia historica bohemica 19 (1998) S. 117146.

${ }^{43}$ Rebitsch (wie Anm. 9) S. 158-165. - Ders.: Matthias Gallas und die Liquidierung Albrechts von Wallenstein. In: Innsbrucker Historische Studien 23-24 (2005) S. 325-378. Ders.: Matthias Gallas (1588-1647). Generalleutnant des Kaisers zur Zeit des Dreißigjährigen Krieges. Eine militärische Biographie (Geschichte in der Epoche Karls V. Bd. 7). Münster 2006. S. 70-111, 373-402.

${ }^{44}$ Rebitsch (wie Anm. 9) S. 158-176.

${ }_{45}$ Büžek/Mat'a (wie Anm. 8) S. 295. 
serlichen Heeres der antihabsburgischen Aktivitäten überführten. Diese überbrachte Jaroslav Sezima Rašín von Riesenburg. Es lässt sich nicht ausschließen, dass der genannte böhmische Adlige evangelischer Gesinnung die Dokumente, die schließlich verloren gingen, erst nach Wallensteins Sturz auf Bestellung des Kaiserhofes ausfertigte, um seinen Familienbesitz vor der Konfiskation und seine Familie vor dem Zwangsaufenthalt im Exil zu retten ${ }^{46}$.

Als Wallenstein den richtigen Weg aus dem Labyrinth seiner unschlüssigen Überlegungen nicht finden konnte, wandte Friedrich Schiller seine bittenden Blicke wieder zu den Sternen, von denen er eine Prophezeiung von günstigen Ereignissen zu empfangen erwartete: Zeigt einen Weg mir an, aus diesem Drang, bilfreiche Mächte, einen solchen zeigt mir, den ich vermag zu gehen! ${ }^{47}$ Der Autor des Dramas schuf den Raum seiner künstlerischen Phantasie vor allem in der fiktiven Gestalt des Sohnes von Ottavio Piccolomini, Max, der durch sein Verhalten nicht nur einen kritischen Spiegel für die Charaktereigenschaften der Obersten der Armee Wallensteins abgab, sondern - vor allem in den fiktiven Dialogen mit seinem Vater - es gleichzeitig wagte, die Schritte des unentschlossenen Herzogs von Friedland, den er des Verrats am Kaiser verdächtigte, zu richten ${ }^{48}$.

Schiller entging, dass der Wiener Hof am 18. Februar 1634 das zweite Absetzungspatent gegen den ehemaligen Generalissimus erließ, durch das man sich gleichzeitig an Matthias Gallas, Ottavio Piccolomini, Balthasar Marradas, Rudolf von Colloredo-Waldsee und weitere loyale Truppenführer mit der Aufgabe wandte, die Umgruppierung und Stellungswechsel des kaiserlichen Heeres zu organisieren. Die finanziellen Unkosten, die mit dieser Operation verbunden waren, sollten nicht nur aus der Konfiskation des Besitzes Wallensteins, sondern auch Adam Erdmann Trčkas von Lípa, Wilhelm Wchynskis von Wchynitz und Christian von Ilows beglichen werden, über die die Reichsacht verhängt wurde ${ }^{49}$.

Trotz des geschilderten Verfalls der Armee war sich Schillers Wallenstein offensichtlich nicht bewusst, dass er der Unterstützung seiner Truppenführer, die er im zweiten Pilsner Revers vom 20. Februar 1634 aufs Neue zu einem Treuegelöbnis aufgefordert hatte, nicht mehr sicher sein konnte ${ }^{50}$. Dieses Gelöbnis unterschied sich von dem ersten durch die Formulierung, dass die Obersten an der Seite Wallensteins als treue Untertanen des Kaisers stehen sollten. Sobald Wallenstein dann erst mit Verzögerung von seiner wiederholten Absetzung als Oberbefehlshaber der kaiserlichen Armee und dem Verhängen der Reichsacht von Adam Erdmann Trčka erfuhr, entschloss er sich, sein Lager bei Pilsen zu verlassen. Er brach am 22. Feb-

\footnotetext{
${ }^{46}$ Polišenský/Kollmann (wie Anm. 6) S. 208. - Bílek (wie Anm. 12) I. Bd. S. 453-454.

47 Schiller (wie Anm. 5) Bd. 2. S. 21.

48 Norbert Oellers: Poetische Fiktion als Geschichte. Die Funktion erfundener Figuren in Geschichtsdramen Schillers. In: Schiller als Historiker (wie Anm. 4) S. 205-217.

${ }^{49}$ Rebitsch (wie Anm. 9) S. 220-221.

50 Polišenský/Kollmann (wie Anm. 6) S. 205. - Rebitsch (wie Anm. 9) S. 221-222.
} 
ruar 1634 zur geplanten Reise über Eger nach Sachsen auf ${ }^{51}$. In Schillers Drama war es Walter Buttler, der Wallenstein die Nachricht über das Verhängen der Reichsacht überbrachte. Dieser irische Oberst gaukelte dem Herzog von Friedland lange scheinbare Treue vor ${ }^{52}$. Einige Tage später gehörte er jedoch zu den Hauptanstiftern der Ermordung Wallensteins, die er im Namen des Kaisers zu begehen befahl: Klar ist die Schuld, der Kaiser hat gerichtet, und seinen Willen nur vollstrecken $w_{i r}{ }^{53}$. Zu seinen Verbündeten zählten der schottische Obristwachtmeister Walter Leslie und der schottische Obristleutnant John Gordon, der gleichzeitig Stadtkommandant von Eger war.

Während die Ermordung von Adam Erdmann Trčka von Lípa, Wilhelm Wchynski von Wchynitz, Christian Freiherr von Ilows und drei weiterer Mitglieder des Stabs des Oberbefehlshabers während eines Festbanketts auf der Egerer Burg in Schillers Darstellung eher in den Hintergrund rückt, konzentriert sich der Autor auf die Schilderung der letzten dramatischen Momente von Wallensteins irdischer Wanderung. Als Schillers Wallenstein auf sein vergangenes Leben zurückblickte und den sich nähernden Tod zu spüren begann, konnte er mit der Sprache der Sterne - die nach den Worten seines Astrologen Giovanni Battista Seni eine deutliche Botschaft vom Verrat falscher Freunde ausstrahlten - Abschied nehmen. Das verräterische Verhalten dieser Personen verkörperte Walter Buttler, der den irischen Offizier seines Dragonerregiments Walter Deveroux in den Abendstunden des 25. Februar 1634 ins Haus des ehemaligen Bürgermeisters auf dem Egerer Marktplatz entsandte, um den ehemaligen Generalissimus umzubringen ${ }^{54}$. Obschon Wallenstein in Schillers Drama - entgegen der historischen Realität - durch die Hand Walter Buttlers, dem der Herzog von Friedland lange vertraut hatte, ermordet wurde, gelang es dem Autor im abschließenden Bild von Treue und Verrat, den erwarteten emotionalen Höhepunkt zu gestalten ${ }^{55}$.

Schillers Wallenstein stellt einen unschlüssigen Helden dar, der an der Grenze zwischen Guten und Bösen schwebte, der im Interesse einer schnellen Beendigung des langwierigen Kriegskonflikts mit dem Gedanken an Treuebruch gegenüber dem Kaiser spielte ${ }^{56}$. Obwohl Friedrich Schiller die Ursachen für den Sturz Wallensteins nicht erläuterte und seinen angeblichen Verrat am herrschenden Haus Habsburg nicht bestätigte ${ }^{57}$, schilderte er den Herzog von Friedland als Friedensstifter, der sich für eine schnelle Beendigung des Kriegskonflikts einsetzte. Auch

51 Polišenský/Kollmann (wie Anm. 6) S. 205-206. - Rebitsch (wie Anm. 9) S.222-225. Kollmann, Valdštejnův konec (wie Anm. 9) S. 168-191.

52 Janáček (wie Anm. 6) S. 506-510.

53 Schiller (wie Anm. 5) Bd. 2. S. 98.

${ }^{54}$ Janáček (wie Anm. 6) S.518-523. - Polišenský/Kollmann (wie Anm.6) S. 206-207. Rebitsch (wie Anm. 9) S. 222-225. - Kollmann, Valdštejnův konec (wie Anm. 9) S. 168-191.

55 Oellers (wie Anm. 3) S. 102-103.

${ }_{56}$ Mann (wie Anm.2) S. 98-109. - Reinhardt (wie Anm.3) S. 416-437. - Rebitsch (wie Anm. 9) S. 8-10.

57 Schieder (wie Anm. 4) S. 31-54. 
wenn die moderne tschechische historische Forschung den steilen Aufstieg Wallensteins der Karriere eines Kriegsgewinnlers gegenüberstellte ${ }^{58}$, wäre es aber nicht richtig anzunehmen, dass die baldige Beendigung dieses Krieges für den Oberbefehlshaber der kaiserlichen Armee vorteilhaft gewesen wäre. Für Schiller stand an erster Stelle das künstlerische Bild von Treue und Verrat, das durch die Revolte Wallensteins gegen die eingeprägte Ordnung der Tradition entworfen wurde, während er die Aussage der historischen Quellen offensichtlich für zweitrangig hielt ${ }^{59}$. Obwohl es Schiller an Kenntnissen über die politische und konfessionelle Entwicklung im Königreich Böhmen, die er aus dem Werk des Historikers Martin Pelcl „Kurzgefasste Geschichte der Böhmen“ schöpfte, nicht mangelte, war ihm der Quellenreichtum der adligen Archive nicht bekannt. Aus dem Werk Pelcls übernahm Schiller offenbar die Verherrlichung des Hussitentums wie auch die Hochschätzung religiöser und politischer Freiheiten der böhmischen Stände in der Zeit vor der Schlacht am Weißen Berg ${ }^{60}$.

Friedrich Schiller befasste sich in den abschließenden Auftritten des letzten Teiles seines Dramas nicht mit dem Verlauf der Konfiskationen des Grundbesitzes Wallensteins und seiner Anhänger, die unmittelbar nach dem Erlass des zweiten Absetzungspatents gegen den ehemaligen Oberbefehlshaber begannen und sich noch einige Jahre nach seinem Tod fortsetzten. Die Güterkonfiskationen nach Wallensteins Sturz unterschieden sich von den ersten beiden Konfiskationswellen erheblich $^{61}$. Diese liefen im Königreich Böhmen als unmittelbare Folgen der Schlacht am Weißen Berg und des darauffolgenden Einfalls der sächsischen Truppen ab. In diesen beiden Konfiskationswellen verordnete der Kaiser, das Vermögen des antihabsburgisch gesinnten böhmischen Adels evangelischen Bekenntnisses zu beschlagnahmen. Obwohl die Vertrauten des Kaisers und Offiziere der kaiserlichen Armee (Johann Ulrich von Eggenberg, Karl Bonaventura Buquoy, Balthasar Marradas) einen geringen Teil des konfiszierten Vermögens erwarben ${ }^{62}$, gingen die meisten Güter in den Besitz des katholischen, im Königreich Böhmen eingesessenen Adels über, der zu den treuen Anhängern der habsburgischen Politik ge-

${ }^{58}$ Mat'a (wie Anm. 20) S. 458-464.

59 Dahn (wie Anm. 4) S. 109-126. - Mannigel (wie Anm. 4) S. 121-123.

60 Oellers (wie Anm. 3) S. 99-100.

61 Bílek (wie Anm. 12). - Tomáš Knoz: Pobělohorské konfiskace. Moravský průběh, středoevropské souvislosti, obecné aspekty [Die Konfiskationen nach dem Weißen Berg. Mährischer Verlauf, mitteleuropäische Zusammenhänge, allgemeine Aspekte]. Brno 2006. S. 383-407. - Bůžek/Mat'a (wie Anm. 8) S. 294-296.

${ }_{62}$ Čornej (wie Anm. 12) S. 181. - Walther Ernst Heydendorff: Die Fürsten und Freiherren zu Eggenberg und ihre Vorfahren. Graz 1965. - Peter Broucek: Feldmarschall Buquoy als Armeekommandant 1618-1620. In: Der Dreißigjährige Krieg. Beiträge zu seiner Geschichte (Schriften des Heeresgeschichtlichen Museums in Wien 7). Wien 1976. S. 25-76. - Olivier Chaline: Charles-Bonaventure de Logueval, comte de Buquoy (1571-1621). In: XVII ${ }^{\mathrm{e}}$ Siècle 60 (2008) S. 399-422. - Josef Forbelský: Španělé, Říše a Čechy v 16. a 17. století. Osudy generála Baltasara Marradase [Spanier, Reich und Böhmen im 16. und 17. Jahrhundert. Schicksal des Generals Balthasars Marradas]. Praha 2006. 
hörte. Durch den Ankauf der konfiszierten und unter Wert verkauften Güter erweiterte nicht nur Wallenstein zu Beginn der zwanziger Jahre des 17. Jahrhunderts sein Vermögen, sondern auch Maria Magdalena Trčka von Lípa, geborene von Lobkowicz, Polyxena von Lobkowicz, geborene von Pernstein, und Jaroslav Borzita von Martinitz ${ }^{63}$.

Durch die Konfiskationsprozesse nach Wallensteins Sturz kam es zur Zersplitterung ausgedehnter adeliger Herrschaften mit entwickelter und ertragreicher landwirtschaftlicher wie auch handwerklicher Produktion in Nord- und Ostböhmen, deren Fundamente bereits weit vor der Schlacht am Weißen Berg gelegt wurden. Durch den kaiserlichen Beschluss wurden die Dominien Wallensteins, Trčkas von Lípa und Wilhelm Wchynskis von Wchynitz in eine Reihe autonomer Gebiete aufgeteilt. Die einzelnen Herrschaften erhielten meistens Regimentsobersten für ihre Treue und als Ersatz für ausstehende finanzielle Forderungen. Die Begünstigten kamen aus verschiedenen Ländern Europas und verteidigten die Interessen der Habsburger auf den Schlachtfeldern des Dreißigjährigen Kriegs ${ }^{64}$. Gleichzeitig mit dem Erwerb des Grundbesitzes nahm der Kaiser seine treuen Truppenführer als Einwohner des Königreichs Böhmen mit der Grafenwürde an, die jedoch in den Augen der Repräsentanten alter böhmischer Adelsfamilien nicht als Ausdruck vornehmer Herkunft wahrgenommen wurden ${ }^{65}$. Infolge der Konfiskationen des Vermögens wechselte in den zwanziger und dreißiger Jahren des 17. Jahrhunderts mehr als die Hälfte des adeligen Besitzes in Böhmen den Besitzer.

Ferdinand II. legitimierte Wallensteins Mord durch ostentative Schenkungen des Grundbesitzes, womit er seine engsten Vertrauten belohnte. Ihre persönlichen Verdienste um die Beseitigung des ehemaligen Oberbefehlshabers bemaß er mit der Fläche der geschenkten Herrschaften und der wirtschaftlichen Bedeutung der obrigkeitlichen Unternehmen. Den größten Teil des Besitzes Wallensteins und seiner Verbündeten erwarb Matthias Gallas. Nachdem der ursprünglich arme Gallas, ein Lehensmann des Bischofs von Trient, bereits im Jahre 1632 in den Reichsgrafenstand erhoben worden war, revanchierte sich der Kaiser nach Wallensteins Sturz großzügig für seine treuen Dienste. Er schenkte dem provisorischen Oberbefehlshaber der kaiserlichen Armee die Herrschaften Friedland und Reichenberg ${ }^{66}$. Da die Residenzstadt Wallensteins bereits Feldmarschall Rudolf Freiherr von Tiefenbach erhalten hatte ${ }^{67}$, konnte sich Gallas nicht in Jitschin niederlassen. So bevor-

63 Čornej (wie Anm. 12) S. 178-185. - Kollmann, Valdštejnův konec (wie Anm. 9) S. 200.

${ }^{64}$ Čornej (wie Anm.12) S.185-189.

${ }^{65}$ Bǔžek, Adelslandschaft (wie Anm. 8) S. 28-31.

66 Bílek (wie Anm.12) II. Bd. S.732-832. Bes. S.762, 773. - Rebitsch, Matthias Gallas (1588-1647) (wie Anm. 43) S. 385-402. - Ders. (wie Anm. 9) S.161-165. - Martin Krummholz: Gallasové (1634-1757) [Gallas (1634-1757)]. In: Clam-Gallasův palác. Johann Bernhard Fischer von Erlach. Architektura - výzdoba - život rezidence [Palais Clam-Gallas. Johann Bernhard Fischer von Erlach. Architektur - Ausschmückung - Leben der Residenz]. Hg. von dems. Praha 2007. S. 11-30. Hier S. 12ff.

${ }_{67}$ Bílek (wie Anm. 12) II. Bd. S. 777-778. - Rebitsch (wie Anm. 9) S. 165. 
zugte er Südtirol, seine Heimat. Als Ersatz erwarb er die ausgedehnte Herrschaft Smiřice/Smiritz, die den Trčkas von Lípa gehörte, das Haus von Wilhelm Wchynski von Wchynitz in der Prager Altstadt und eine wertvolle Sammlung silberner Gegenstände, die nach der Ermordung Christian Freiherrn von Ilows beschlagnahmt wurde ${ }^{68}$. Sein Enkel, Graf Johann Wenzel Gallas, ließ zu Beginn des 18. Jahrhundert an der Stelle des geschenkten Renaissancehauses im Zentrum Prags ein prunkvolles Palais erbauen, das zu den bedeutendsten Baudenkmälern des Barocks in Zentraleuropa gehört ${ }^{69}$. Die Erteilung des Inkolatsrechts im Königreich Böhmen ermöglichte es Matthias Gallas, das ganze Vermögen nach seinem Tod im Besitz der Familie zu halten, so dass sich diese in der Mitte des 17. Jahrhunderts zu den reichsten Adelsfamilien in Böhmen zählen konnte ${ }^{70}$.

Der Schwager von Matthias Gallas, Johann von Aldringen, wurde im gleichen Jahr wie sein Verwandter in den Grafenstand erhoben. Für seine militärischen Verdienste und als Ersatz für seine Forderungen bei der Hofkammer schenkte ihm Ferdinand II. ein Jahr nach Wallensteins Tod die Herrschaft Teplice/Töplitz in Nordböhmen, die Wilhelm Wchynski von Wchynitz konfisziert wurde ${ }^{71}$. Der erfolgreichste unter den habsburgischen Feldherrn, Ottavio Piccolomini, erhielt vom Kaiser die ausgedehnte Herrschaft Náchod/Nachod, die vor den Konfiskationen den Trčkas von Lípa gehört hatte ${ }^{72}$. Ottavio Piccolomini ließ die Decke des Hauptsaals im Schloss zu Nachod mit Fresken schmücken, die den triumphalen Einzug des großen Feldherrn, vor dem die geschlagenen Feinde in Scharen flohen, in den Olymp des ewigen Ruhms darstellten. In der Nachbarschaft dieser Szene bildete der Maler eine Vedute des Schlosses zu Nachod ab. In ihrer symbolischen Bedeutung spiegelten sich die militärischen Erfolge Ottavio Piccolominis in den Diensten am Hause Habsburg wider. Sie dienten als Mittel der Selbstpräsentation des

68 Bílek (wie Anm. 12) II. Bd. S. 707-708, 867. - Rebitsch (wie Anm.9) S. 165. - Ders.: Matthias Gallas (1588-1647) (wie Anm. 43) S. 394-395.

${ }^{69}$ Mit der Zusammenfassung der Literatur Martin Krummbolz, Pražský palác [Das Prager Palais]. In: Clam-Gallasův (wie Anm. 66) S. 81-102.

70 Rebitsch: Matthias Gallas (1588-1647) (wie Anm. 43) S. 395.

71 Bílek (wie Anm. 12) II. Bd. S. 861-865. - Michaela Hrubá: Prominentní emigrant Vilém Vchynský (Kinský) a jeho majetek v severozápadních Čechách [Der prominente Emigrant Wilhelm Vchynski und sein Vermögen in Nordwestböhmen]. In: Víra nebo vlast? Exil v českých dějinách raného novověku [Glauben oder Heimat? Exil in der tschechischen Geschichte der Frühen Neuzeit]. Hg. von ders. Ústí nad Labem 2001. S. 210-221. - Rebitsch (wie Anm. 9) S. 165-168.

72 Bílek (wie Anm.12) II. Bd. S.680. - Josef Dostál: Opočenský zámek roku 1635 [Das Schloss in Opočno/Opotschno im Jahre 1635]. In: Časopis Společnosti přátel starožitností 43 (1935) S. 183-188. - Ders.: Poslední boj. Příspěvek k dějinám trčkovských konfiskací [Der letzte Kampf. Ein Beitrag zur Geschichte der Trčkas Konfiskationen]. In: Sborník Archivu ministerstva vnitra 9 (1936) S. 55-122. - Ders.: Z historie trčkovských konfiskací [Aus der Geschichte der Trčkas Konfiskationen]. In: Český časopis historický 50 (1947-1949) S. 165184. 
italienischen Adeligen im Königreich Böhmen ${ }^{73}$. Seine gesellschaftliche Karriere erreichte im Jahre 1650 ihren Höhepunkt, als er in den Reichsfürstenstand erhoben wurde $^{74}$. Die Erben Ottavio Piccolominis hätten sich zu den einflussreichsten Adelsfamilien im Lande zählen können, wären sie nicht von Unfruchtbarkeit und psychischen Krankheiten verfolgt gewesen ${ }^{75}$.

Auch der gesellschaftliche Aufstieg des Feldmarschalls Rudolf Colloredo-Waldsee wurde durch seine militärische Karriere in den habsburgischen Diensten bedingt. Diese brachte ihm nach Wallensteins Tod die reiche Herrschaft Opočno/ Opotschno, die sich ursprünglich im Besitz der Trčkas von Lípa befand. Der neue Besitzer dieser Herrschaft und des prunkvollen Schlosses stieß schnell zu den reichsten Adeligen des Königreichs Böhmen vor. Als Großprior des Malteserordens in Böhmen ließ er sich auf der Kleinseite in Prag einen prachtvollen Garten anlegen ${ }^{76}$.

Walter Leslie, schottischer Feldherr im habsburgischen Dienst und einer der Beteiligten an der Ermordung Wallensteins, befahl die Decke des Hauptsaals seiner neuen Residenz auf dem Schloss in Nové Město nad Metují/Neustadt an der Mettau, das ihm der Kaiser nach der Konfiskation der Güter der Trčkas von Lípa zuteilte, mit Motiven aus den Schlachtfeldern des Dreißigjährigen Krieges auszuschmücken ${ }^{77}$. Der erfolgreiche Kriegsführer verwandelte sich zu einem Kriegsexperten und Diplomat, der in Böhmen und in der Steiermark Vermögen anhäufte, die seine Verwandten, die in den folgenden Jahrzehnten aus Schottland nach Mitteleuropa kamen, übernahmen ${ }^{78}$.

Obwohl Matthias Gallas, Johann von Aldringen, Ottavio Piccolomini, Rudolf Colloredo-Waldsee und Walter Leslie den größten Teil an den Konfiskationen des

73 Jiří Kubeš: Reprezentační funkce sídel vyšší šlechty z českých zemí (1500-1740) [Die Repräsentationsfunktion der Sitze des höheren Adels aus den böhmischen Ländern (15001740)]. Diss. České Budějovice 2005. S. 232. - Ders.: Hlavní sál - sebereflexe šlechty ve výzdobě společenských místností venkovských sídel (na př́kladě českých zemí 17. a první poloviny 18. století) [Der Hauptsaal - eine Selbstreflexion des Adels in der Ausschmückung der gesellschaftlichen Räume in den ländlichen Residenzen (am Beispiel der böhmischen Länder des 17. und der ersten Hälfte des 18. Jahrhunderts)]. In: Česko-slovenská historická ročenka (2005) S. 31-59.

${ }^{74}$ Harry Schlip: Die neuen Fürsten. Zur Erhebung in den Reichsfürstenstand und zur Aufnahme in den Reichsfürstenrat im 17. und 18. Jahrhundert. In: Liechtenstein - Fürstliches Haus und staatliche Ordnung. Geschichtliche Grundlagen und moderne Perspektiven. Hg. von Volker Press/Dietmar Willoweit. München/Wien ${ }^{2} 1988$. S. 249-292.

75 Mat'a (wie Anm. 20) S. 462.

76 Bílek (wie Anm. 12) II. Bd. S. 763. - Mat'a (wie Anm. 20) S. 462.

77 Bílek (wie Anm. 12) II. Bd. S. 680-681. - Kubeš, Hlavní sál (wie Anm. 73) S. 45-46.

${ }^{78}$ Karl Minha: Walter Graf Leslie (1606-1664). Feldmarschall, Grenzgeneral, Großbotschafter. Mit Vorbemerkung, Nachwort und einer Biographie des Autors von Peter Broucek. In: Wallensteins Werden und Streben, Wirken und Sterben (Materialien zum Vortragszyklus Gesellschaft für Österreichische Heereskunde). Hg. von Fritz Baier/Peter Broucek. Wien 1984. S. 67-153. 
Vermögens Wallensteins und seiner Anhänger im Königreich Böhmen erwarben, kamen auch die anderen Obersten und Generäle, die an der Beseitigung des Herzogs von Friedland beteiligt waren, nicht zu kurz. Viele unter ihnen wurden in höhere militärische Ränge befördert, anderen ermöglichte der Kaiser eine schnelle Erhebung in den Reichsgrafenstand ${ }^{79}$. Eine Reihe kleinerer Herrschaften, vor allem auf dem ehemaligen Dominium Wallensteins, wurde nicht nur den Truppenführern italienischer Herkunft Francesco Caretto di Grana Graf von Millesimo und Giacomo Graf von Strozzi zugeteilt, sondern auch Heinrich Graf Schlick und Johann Ludwig Hektor Graf von Isolani, der das Kommando über die kroatischen Truppen innehatte. Der Kaiser belohnte die Kommandanten John Gordon und Walter Buttler wie auch Offiziere schottischer und irischer Herkunft in seinem Dragonerregiment großzügig, die Wallenstein und seine Vertrauten ermordet hat$\operatorname{ten}^{80}$. Die Lebensschicksale von Dionysius MacDaniel, Walter Deveroux, Robert Geraldin und anderer Kriegsabenteurer verschwanden jedoch schnell wieder aus den Zeugnissen bekannter schriftlicher Quellen.

Die Übertragungen konfiszierter Güter an die Obersten der kaiserlichen Armee, die den Habsburgern treu dienten, und ihre Niederlassung im Königreich Böhmen riefen bei einigen zeitgenössischen Beobachtern widersprüchliche Gefühle hervor. Die Patrioten warfen den Neuankömmlingen die Unkenntnis der tschechischen Sprache einerseits und niedrige Standeszugehörigkeit andererseits vor. Beiderlei Vorwürfe standen im Widerspruch mit den geltenden Grundsätzen der Verneuerten Landesordnung für das Königreich Böhmen. Gemäß diesem Gesetz wurde das Tschechische im offiziellen Verkehr der deutschen Sprache gleichgesetzt. Die neuangekommenen Adeligen verbreiteten im tschechischen Milieu allerdings vor allem Kenntnisse der italienischen und spanischen Sprache. Die Grundlagen des Tschechischen brauchten sie nur, um sich mit den obrigkeitlichen Beamten auf den erworbenen Gütern und mit einigen Soldaten in ihren Regimentern verständigen zu können ${ }^{81}$.

Die Verneuerte Landesordnung regelte die Grundsätze für die Titulatur vornehmer Personen ganz neu ${ }^{82}$. Dem Kaiser gelang es in den böhmischen Ländern, ähnlich wie in anderen Teilen der Habsburgermonarchie, eine gleiche Adelstitulatur nach dem Vorbild des Römisch-Deutschen Reiches durchzusetzen. Die Altehr-

79 Vgl. Georg Schmidt: Voraussetzung oder Legitimation? Kriegsdienst und Adel im Dreißigjährigen Krieg. In: Nobilitas. Funktion und Repräsentation des Adels in Alteuropa (Veröffentlichungen des Max-Planck-Instituts für Geschichte 133). Hg. von Otto Oexle/ Werner Paravicini. Göttingen 1997. S. 431-451.

80 Bílek (wie Anm. 12) II. Bd. S. 732-832.

${ }^{81}$ Václav Bůžek u.a.: Společnost českých zemí v raném novověku. Struktury, identity, konflikty [Die Gesellschaft der böhmischen Länder in der frühen Neuzeit. Strukturen, Identitäten, Konflikte]. Praha 2010. S.77-78, 96-98.

82 Bǔžek/Mat'a (wie Anm. 8) S. 293-294. - Bủžek, Adelslandschaft (wie Anm. 8) S. 28-30. - Ders.: Frühneuzeitliche Adelsgeschichte in der tschechischen Geschichtsschreibung (im Druck). 
würdigkeit des Geschlechtes wurde durch die Verdienste des Individuums und durch seine Treue zur regierenden Dynastie ersetzt. Gemäß der Verneuerten Landesordnung wurde der Klerus zum ersten Stand in Böhmen wie in Mähren erklärt. Der Erzbischof war demnach allen Adeligen des höheren und niederen Standes übergeordnet. Der Herrenstand nahm in der neuen Gesellschaftsordnung die zweite Stelle ein. Über die Aufnahme in ihren Stand entschieden nun nicht mehr die Standesmitglieder bei den Sitzungen des Landtags, wie es vor 1620 üblich war, sondern es genügte genügte ein Privilegium des Herrschers für die Neuaufnahme, das die Böhmische Hofkanzlei ausstellte. Bis zur Verkündigung der Verneuerten Landesordnung berechtigten Fürsten- und Grafentitel ihre Träger in Böhmen und Mähren in keiner Weise zur Präzedenz vor den einheimischen Herren. Wenn ein in den böhmischen Ländern ansässiger Adeliger seine Grafen- oder Fürstenwürde inszenierte, wurde er dennoch nur für ein gewöhnliches Mitglied des Herrenstandes gehalten. Gemäß der Verneuerten Landesordnung standen nun die Fürsten und Grafen an der Spitze des Herrenstandes, denen der Vorrang vor den Herren eingeräumt wurde.

Von insgesamt 17 neuen Fürsten, denen in den Jahren 1620 bis 1740 eine Reichswürde verliehen wurde, besaßen neun Fürsten Güter auch in den böhmischen Ländern. Aus den Konfiskationen nach Wallensteins Sturz profitierten nur die Piccolomini ${ }^{83}$. Der steile soziale Aufstieg neuer Fürsten rief in den Augen der Vertreter der alten Reichsfürstenhäuser Missfallen hervor. Diese ignorierten lange Zeit die neuen Emporkömmlinge ${ }^{84}$. Eines Grafentitels konnten sich vor dem Ende des 17. Jahrhunderts alle bedeutenden Herrenstandsfamilien rühmen, die nach $1620 \mathrm{im}$ Königreich Böhmen blieben. Um die Mitte des 18. Jahrhunderts bildeten die Grafen mehr als zwei Drittel der Mitglieder des Herrenstandes, was ungefähr $200 \mathrm{Fa}-$ milien darstellte. Die Fürsten und Grafen besaßen in derselben Zeit etwa $90 \%$ des gesamten adeligen Vermögens im Land. Der niedere Adelsstand konnte um die Mitte des 18. Jahrhunderts nur einen vergleichsweise geringfügigen Besitzumfang für sich deklarieren. Die absolute Mehrheit der reicheren Angehörigen des niederen Adels war im Jahrhundert nach der Schlacht am Weißen Berg in den höheren Stand aufgestiegen. Dies ging nun wesentlich leichter als früher. Der niedere Adel, dem die Verneuerte Landesordnung die dritte Stelle in der Hierarchie der ständischen Gesellschaft neben dem Klerus und dem Herrenstand zugewiesen hatte, verlor als Stand in der Zeit nach der Schlacht am Weißen Berg seinen ehemaligen politischen

83 Bůžek/Mat'a (wie Anm. 8) S. 299-302. - Thomas Klein: Die Erhebungen in den weltlichen Reichsfürstenstand 1550-1806. In: Blätter für deutsche Landesgeschichte 122 (1986) S. 137-192. Hier S. 137-163.

${ }^{84}$ Hans Jürgen Jüngling: Die Heiraten des Hauses Liechtenstein im 17. und 18. Jahrhundert. Konnubium und soziale Verflechtungen am Beispiel der habsburgischen Hocharistokratie. In: Liechtenstein (wie Anm. 74) S. 329-346. Hier S. 344f. 
Einfluss wie seine materielle Basis und zersetzte sich im Prinzip noch vor der Mitte des 18. Jahrhunderts ${ }^{85}$.

Schwerwiegende Eingriffe des Herrschers in die Struktur, Titulatur und Vermögensverhältnisse des Adels trugen in der Zeit nach der Schlacht am Weißen Berg zum allmählichen Verfall ihrer ehemaligen Standes- und Landesidentität bei. Nach 1620 stellten die Adligen katholischer Gesinnung eine kaum mehr homogene soziale Gruppe dar, die im Königreich Böhmen, in anderen Ländern der Habsburgermonarchie und im Römisch-Deutschen Reich einen Teil ihres Vermögens und Eigentums besaß, sich in verschiedenen Sprachen verständigte, internationale Heiratsallianzen schloss, Kavalierstouren nach Italien, Spanien und Frankreich unternahm, und die es schaffte, die zunehmende Anziehungskraft des Kaiserhofes in Wien für ihren persönlichen Karriereaufstieg zu nutzen. Darüber hinaus bestimmte und beeinflusste sie durch ihren Lebensstil die Gestalt der materiellen und geistlichen Kultur des angehenden Barocks ganz wesentlich ${ }^{86}$.

Die Stützen der kollektiven Identität vornehmer Personen in der Zeit nach der Schlacht am Weißen Berg wären ohne näheren Einblick in die Werdegänge und Karrieren, in den Lebensstil und in den wirtschaftlichen Hintergrund der Angehörigen einiger Generationen der Neuankömmlinge, die in der Geschichte des Landes dauerhaft ihre Spuren hinterließen und die Gestalt ihrer Landschaft beeinflussten, nicht näher zu profilieren. Einige von ihnen ließen sich in den dreißiger Jahren des 17. Jahrhunderts auf ihren Herrschaften im Königreich Böhmen nieder, die früher Wallenstein und seine Anhänger besessen hatten. Obwohl sie in Böhmen reiche Familienarchive hinterließen, wandte sich die tschechische Geschichtsforschung ihren Lebensschicksalen erst in der Gegenwart langsam zu. Das verspätete Interesse an der Adelsgeschichte nach 1620 wird jetzt nicht mehr durch das mythische Trauma der habsburgischen Herrschaft begründet, sondern ist heuristischer, sprachlicher, methodischer und vor allem konzeptioneller $\mathrm{Art}^{87}$.

${ }^{85}$ Eila Hassenpflug-Elzholz: Böhmen und die böhmischen Stände in der Zeit des beginnenden Zentralismus. Eine Strukturanalyse der böhmischen Adelsnation um die Mitte des 18. Jahrhunderts. München/Wien 1982. S.312-371.

${ }^{86}$ Bůžek/Mat'a (wie Anm. 8) S. 292-321.

87 Mit der Zusammenfassung der Literatur und im breiteren historiografischen Kontext Bůžek, Adelsgeschichte (wie Anm. 82). - Ders./Josef Hrdlička/Pavel Král/Zdeněk Vybíral: Věk urozených. Šlechta v českých zemích na prahu novověku [Das Zeitalter der Hochgeborenen. Der Adel in den böhmischen Ländern zu Beginn der Neuzeit]. Praha-Litomyšl 2002. - Mat'a (wie Anm. 20). - Ivo Cerman: Šlechtická kultura v 18. století. Filozofové, mystici, politici [Die adelige Kultur im 18. Jahrhundert. Die Philosophen, Mystiker, Politiker]. Praha 2011. - Vítězslav Prchal: Válka, zbraně a zbroj v reprezentačních strategiích české a moravské aristokracie v letech 1550-1750 [Krieg, Waffen und Rüstung in den Repräsentationsstrategien der böhmischen und mährischen Aristokratie in den Jahren 1550-1750]. Diss. Praha 2012. 